\title{
Rancang Bangun Alat Pendeteksi kelembaban tanah dan Penyiram Otomatis Berbasis Arduino Uno
}

\author{
Suleman ${ }^{1}$, Aziz Setyawan $\mathrm{H}^{2}$, Devy Ferdiansyah ${ }^{3}$, Pas Mahyu Akhirianto ${ }^{4}$, Nanang \\ Nuryadi ${ }^{5}$
}

\author{
1,2,3,4,5 Prodi Teknologi Komputer, Universitas Bina Sarana Informatika \\ 1suleman.sln@bsi.ac.id, 2aziz.aiz@bsi.ac.id, ${ }^{3}$ devy.ferdiansyah@bsi.ac.id, ${ }^{4}$ pas.pma@bsi.ac.id, \\ 5nanang.nyd@bsi.ac.id
}

\begin{abstract}
Plants are living things that need water for growth, so plant growth affects the amount of water and nutrients that can be absorbed properly in the growth process. Plants obtain water through the soil which is absorbed by the roots, but plants with short roots such as mustard greens, tomatoes, chilies, and other vegetables find it difficult to reach deeper water. To maintain the quality of soil moisture in order to remain stable, special handling is needed, namely routine watering with attention to the percentage level of moisture in the range of $50 \%-70 \%$. Currently, monitoring of plant watering is still done manually. This has several shortcomings, including requiring more manpower for monitoring, the higher the cost. Therefore, the authors conducted observations and experiments to provide solutions or problems, namely by designing an arduinobased soil moisture detector and automatic sprinkler, the results obtained from the design of the tool were: Soil Moisture Sensor which functions as an input successfully detects Soil moisture value (if the soil is dry) the water pump will automatically water it.
\end{abstract}

Keywords - The Design, Automatic Springklers, Automatic Vegetable Watering, Arduino Uno.

Abstrak: Tanaman merupakan mahluk hidup yang membutuhkan air untuk pertumbuhan, sehingga pertumbuhan tanaman berpengaruh pada jumlah air dan unsur hara yang dapat diserap secara baik dalam proses pertumbuhan. Tanaman memperoleh air melalui tanah yang diserap oleh akar, namun tanaman berakar pendek seperti sawi, tomat, cabai, dan sayuran yang lain sulit untuk menjangkau air lebih dalam. Untuk menjaga kualitas kelembaban tanah agar tetap stabil diperlukan penanganan khusus yaitu penyiraman rutin dengan memperhatikan tingkat persentase kadar air berkisar 50\%-70\%. Saat ini, monitoring penyiraman tanaman masih dilakukan secara manual. Hal ini memiliki beberapa kekurangan, diantaranya membutuhkan lebih banyak tenaga manusia untuk monitoring, biaya (cost) yang dikeluarkan semakin tinggi. Atas dasar itu itu penulis bermaksud melakukan pengamatan langsung dan eksperimen untuk memberikan solusi atau permasalahan tersebut yaitu dengan merancang alat pendeteksi kelembaban tanah dan penyiram otomatis berbasis arduino, dari hasil rancang bangun alat tersebut didapat hasil: Sensor Kelembaban Tanah (Soil Moisture Sensor) yang berfungsi sebagai input berhasil mendeteksi nilai kelembaban tanah (jika kondisi tanah kering) maka pompa air akan secara otomatis melakukan penyiraman.

Kata kunci: Rancang Bangun, Alat Penyiram Otomatis, Penyiram Sayuran Otomatis, Arduino Uno

This is an open access article distributed under the Creative Commons Attribution License, which permits unrestricted use, distribution, and reproduction in any medium, provided the original work is properly cited. O2019 by author and IJSE-Indonesian Journal on Software Engineering.

\section{A. PENDAHULUAN}

Tanaman merupakan mahluk hidup yang membutuhkan air untuk pertumbuhan alaminya, sehingga pertumbuhan tanaman berpengaruh pada jumlah air dan unsur hara yang dapat diserap secara baik dalam proses pertumbuhan. Tanaman memperoleh air melalui tanah yang diserap oleh akar, namun untuk tanaman berakar pendek seperti sawi, tomat, cabai, dan sayuran yang lain sulit untuk menjangkau air lebih dalam. Selain kedalaman dan tingkat elevasi tanah yang mempengaruhi jumlah air tanah, selain itu juga dipengaruhi oleh tingkat kelembaban 
permukaan tanah. Untuk menjaga kualitas kelembaban tanah agar tetap stabil maka diperlukan penanganan khusus yaitu penyiraman secara rutin dengan memperhatikan tingkat persentase kadar air berkisar 50\%-70\%. (Asniati, Ery Muchyar Hasiri, 2017).

Pada saat ini, monitoring penyiraman tanaman masih dilakukan dengan cara manual. Hal ini memiliki beberapa kekurangan, diantaranya membutuhkan lebih banyak tenaga manusia untuk monitoring tumbuh kembang tanaman yang justru menambah biaya perawatan, sulitnya memantau kelembaban tanah dan suhu udara yang dibutuhkan tanaman. (Widiharto, 2017).

Selain negara maritim, Indonesia juga merupakan negara agraris yang mempunyai dua musim, yaitu musim penghujan dan musim kemarau. Tanaman tidak perlu dilakukan penyiraman karena telah mendapatkan air hujan yang cukup. Akan tetapi saat musim kemarau tanaman harus disiram secara teratur sesuai dengan kondisi kelembaban tanah. Para petani biasanya tidak menanam tanaman pangan pada musim kemarau karena takut tidak akan tumbuh dengan baik dan gagal panen. Ketergantungan petani dengan musim menyebabkan produksi petani menurun dan menjadi kendala dalam menyukseskan program swasembada pangan. (Marlina Sari \& Gunawan, 2018).

Alat yang penulis rancang ini dapat digunakan untuk memantau, memberikan informasi tentang kondisi kelembaban tanah dan melakukan penyiraman secara otomatis. Karena kelembaban tanah dapat berubah setiap saat tergantung dengan cuaca dan ketersediaan air yang ada di dalam tanah. Perancangan alat penyiram sayuran otomatis ini dapat dimanfaatkan oleh para petani sayuran untuk mengetahui informasi tentang kelembaban tanah dan melakukan penyiraman sayuran secara otomatis. Sementara pada penelitian sebelumnya dengan judul Rancang Bangun Penyiram Tanaman Berbasis Arduino Uno Menggunakan Sensor Kelembaban YL-39 Dan YL-69 (Jurnal Teknik Elektro dan Komputer, Juli 2018), disana disimpulkan bahwa Alat penyiram tanaman otomatis berbasis Arduino UNO R3 ini dibuat untuk mempermudah pekerjaan manusia dalam hal menyiram tanaman menggunakan sensor kelembaban tanah YL69 kemudian diproses oleh arduino uno dan diinstruksikan kepada android untuk menampilkan nilai kelembaban tanah sesuai dengan $\mathrm{pH}$ tanah, apakah kering, lembab atau basah sesuai dengan pembacaan dari sensor kelembaban tanah dalam bentuk nilai pada Android.

Rancang bangun alat ini menggunakan pengendali mikro single-board yang bernama Arduino Uno sebagai komponen utamanya. Arduino Uno diprogram berdasarkan deteksi sensor kelembaban tanah (Soil Moisture) lahan sayuran tersebut. Sensor kelembaban tanah ini akan membaca nilai kelembaban, kemudian informasi nilai kelembaban tersebut akan dibaca oleh Arduino Uno. Jika hasil pembacaan sensor kelembaban tanah dalam kondisi kering, maka Arduino Uno akan menggerakan pompa air untuk melakukan penyiraman sayuran secara otomatis. Sedangkan jika hasil pembacaan sensor kelembaban tanah dalam kondisi basah, maka Arduino Uno tidak akan melakukan penyiraman sayuran secara otomatis. Setelah itu informasi kelembaban tanah dan status penyiraman akan ditampilkan dengan menggunakan $L C D$ (Liquid Crystal Display). Sehingga dengan perancangan alat seperti ini, para petani menjadi lebih mudah dalam bercocok tanam, hemat tenaga, waktu, dan biaya perawatan.

B. TINJAUAN PUSTAKA

1. Teori IC (Integrated Circuit)

Menurut (Maulana \& Purnama, 2017) "Integrated Circuit (IC) adalah Sirkuit terintegrasi atau yang biasa juga disebut sebagai IC merupakan komponen elektronika yang terbuat dari kumpulan puluhan, ratusan, hingga ribuan transistor, resistor, dioda dan komponen elektronika lainnya".

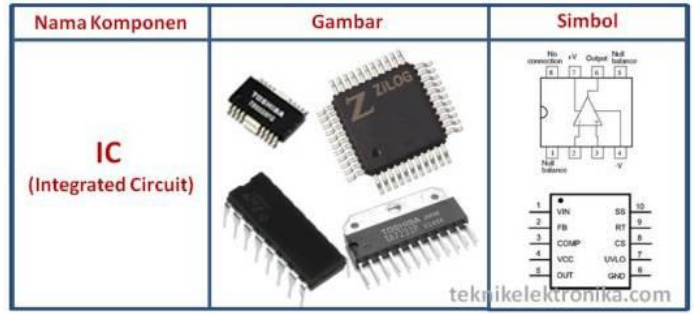

Gambar 1. IC (Integrated Circuit)

2. Sumber Tegangan 
3. Dioda

Sumber tegangan menurut (Fadlilah \& Arifudin, 2018) "Sumber tegangan atau catu daya atau sering disebut dengan power supply adalah sebuah piranti yang berguna sebagai sumber listrik untuk piranti lain". Sedangkan menurut (Nawali, Sherwin, \& Tulung, 2015) "Catu daya merupakan suatu rangkaian yang paling penting bagi rangkaian elektronika".

Pengertian dioda menurut (Oktavia, Hamzah, Rahmondia, \& Umar, 2016) "Dioda merupakan piranti elektronika berfungsi sebagai penyearah arus yaitu dari anoda ke katoda dan tidak sebaliknya".

4. Transistor

Menurut (Nawali et al., 2015) memberikan pengertian bahwa, "Transistor adalah sebuah alat semikonduktor yang bisa digunakan sebagai penguat, sebagai sirkuit penyambung maupun pemutus, menstabilkan tegangan dan lain sebagainya.

5. Kapasitor

Menurut (Nawali et al., 2015) memberikan batasan bahwa "Kapasitor adalah komponen elektronika yang mampu menyimpan muatan listrik, yang terbuat dari dua buah keeping logam yang dipisahkan oleh bahan dielektrik, seperti keramik, gelas, vakum, dan lain-lain".

6. Transformator Menurut (R.Arifin, 2016:372) "Transformator adalah alat yang digunakan untuk menaikan atau menurunkan tegangan listrik".

7. Sensor

Menurut (Ekojono et al., 2018:14) "Sensor adalah komponen yang dapat mengkonversi suatu besaran tertentu menjadi satuan analog sehingga dapat dibaca oleh suatu rangkaian elektronik".

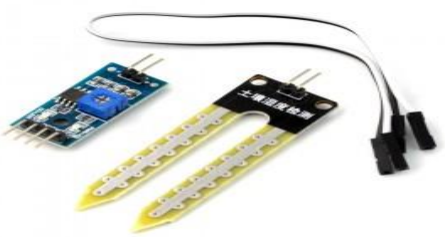

Gambar 2. Bentuk Sensor Kelembaban Tanah

8. Submerssible Pump (Pompa Celup)

Pompa Celup dirancang untuk bekerja dalam memindahkan cairan dari satu titik ke titik lainnya, pompa celup ini dioperasikan benar-benar terendam dalam cairan atau media yang harus di pompa. Jenis pompa ini terdiri dari pompa dan motor tertutup rapat.

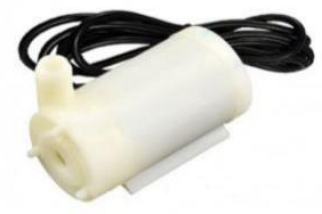

Gambar 3. Bentuk Submersible Pump

9. Relay

Relay adalah saklar (switch) yang dioperasikan secara listrik dan merupakan komponen Elecktro Mechanical (Elektromekanikal) yang terdiri dari 2 bagian utama yakni Elektromagnet (Coi) dan Mekanikal (seperangkat Kontak Saklar/Switch). Saklar berfungsi untuk menghubungkan dan memutuskan arus listrik yang mengalir yang dikontrol sebagai sebuah output dari arduino. 


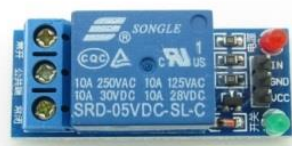

\section{Gambar 4. Relay 5 Volt 1 Channel}

10. LCD (Liquid Crystal Display)

LCD (Liquid Crystal Display) merupakan salah satu jenis display elektronik yang dibuat dengan teknologi CMOS logic yang bekerja dengan tidak menghasilkan cahaya, tetapi memantulkan cahaya yang ada disekelilingnya terhadapat front-lit atau mengtransmisikan cahaya dari back-lit. (Bawotong, Mamahit, \& Sompie, 2015)

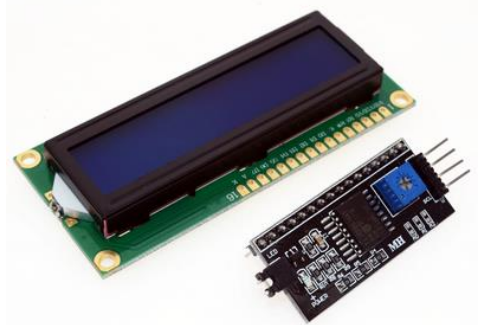

Gambar 5. Bentuk LCD dan I2C

11. Arduino Uno

Menurut (Prayama, Yolanda, \& Pratama, 2018) memberikan batasan bahwa, "Arduino adalah platform hardware dan software yang dapat digunakan oleh penggiat elektronika untuk membuat prototype alat kontroler berbasis mikrokontroller".

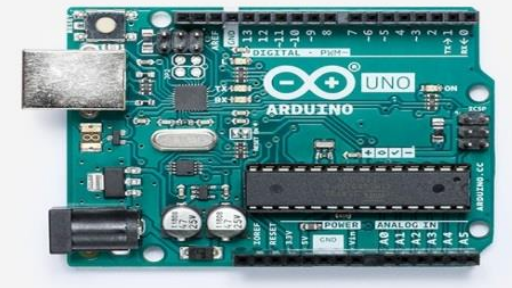

Gambar 6. Arduino Uno

12. Bahasa Pemrograman

Menurut (Sahyar, 2016:2) menyatakan bahwa "Software bahasa (bahasa pemrograman) yaitu program yang digunakan untuk menerjemahkan perintah-perintah yang ditulis dalam bahasa pemrograman ke dalam bahasa mesin (level low/0 atau high/1) agar dapat dimengerti oleh komputer".

13. Software Editor

Dalam pembuatan atau penulisan program, dibutuhkan suatu perangkat lunak untuk merancang dan menjalankan program tersebut. Sama halnya dengan Arduino Uno yang membutuhkan software IDE Arduino untuk memulai atau menulis suatu program. Software ini merupakan software canggih yang ditulis menggunakan Java. IDE Arduino terdiri dari editor program, compiler, dan uploader. (Sokop,et.al, 2016) 


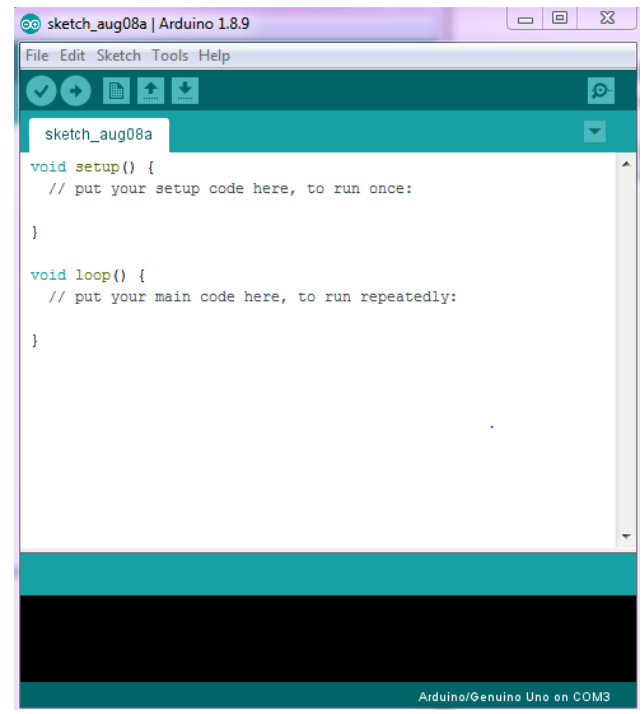

Gambar 7. Tampilan Arduino IDE

\section{METODE PENELITIAN}

Metode penelitian yang penulis gunakan dalam membuat "Rancang Bangun Alat Pendetksi Kelembaban Tanah dan Penyiram Otomatis Berbasis Arduino Uno" ini adalah penggabungan dari beberapa metode yaitu:

1. Metode Observasi

Penulis melakukan pengamatan secara langsung terhadap kegiatan yang berkaitan dengan alat yang dirancang oleh tim penulis. Hasil dari pengamatan tersebut langsung dicatat oleh penulis dan dari pengamatan tersebut dapat disimpulkan rancangan alat yang sesuai dengan kegiatan yang sedang dilakukan.

2. Studi Pustaka

Selain melakukan kegiatan observasi, penulis juga melakukan studi pustaka melalui literatur-literatur atau referensi- referensi pendukung lainnya guna memperkuat hasil praktik dan uji coba dari alat yang penulis rancang ini.

\section{HASIL DAN PEMBAHASAN}

1. Tinjauan Umum Alat

Cara kerja alat ini adalah ketika sensor kelembaban tanah membaca nilai kelembaban tanah, Arduino Uno mengolah dan memproses hasil yang dibaca oleh sensor. Kemudian Aduino Uno mengirimkan hasilnya sebagai output dengan menggerakan atau mematikan pompa, dan menampilkan informasi menggunakan $L C D$ yang berisi kondisi tanah,nilai kelembaban, dan status penyiraman.

2. Blok Rangkaian Alat

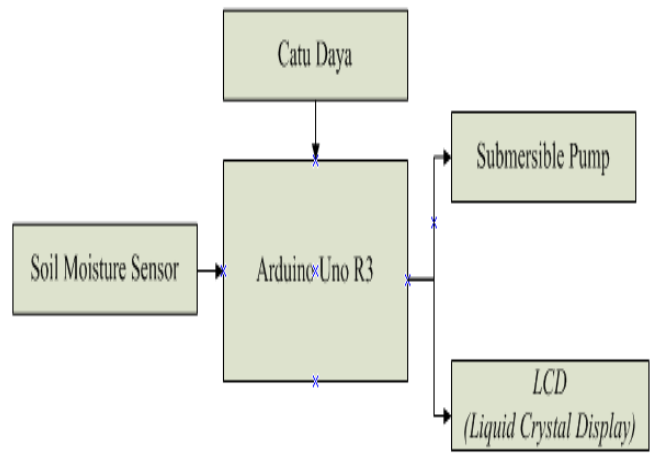

Gambar 8. Blok Rangkaian Alat 
3. Skema Rangkaian Alat

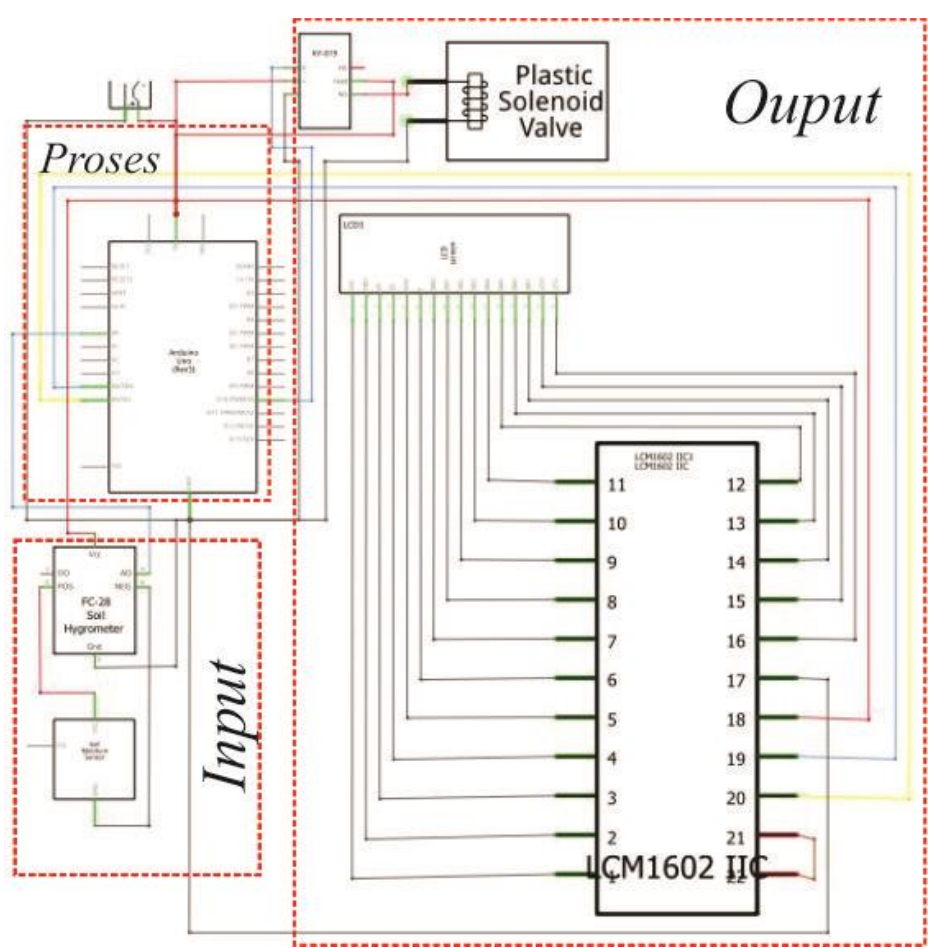

Gambar 9. Skema Rangkaian Alat

\section{Cara Kerja Alat}

Cara kerja alat ini yaitu ketika Arduino Uno diberi tegangan 12 volt pada socket DC, LED pada Arduino Uno akan menyala yang bertanda bahwa alat dapat berfungsi dengan baik. Selanjutnya soil moisture sensor yang sudah dihubungkan dengan pin GND, VCC, dan AO pada Arduino Uno akan mendeteksi kelembaban tanah dengan probe soil moisture sensor yang ditancapkan ke tanah. Setelah sensor mendeteksi nilai kelembaban pada tanah, sensor akan mengirimkan hasil tersebut ke Arduino Uno untuk diolah dan diproses sesuai dengan program yang telah dimasukan. Selanjutnya apabila hasil tersebut telah diketahui, Arduino Uno akan mengirimkan hasil ke relay untuk mengaktifkan atau mematikan submersible pump dan menampilkan kondisi tanah, nilai sensor, dan status penyiraman dengan menggunakan $L C D$ (Liquid Crystal Display).

5. Flowchart Program

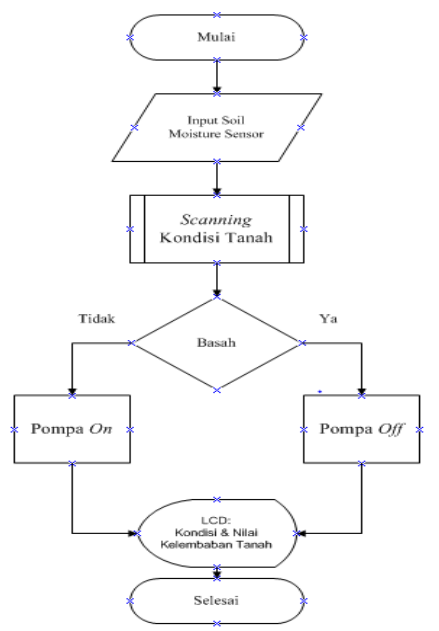

Gambar 10. Flowchart Program 
6. Hasil Percobaan Input

Tabel 1 Hasil Percobaan Input

\begin{tabular}{|c|c|c|c|c|c|c|}
\hline No & Voltase & $\begin{array}{l}\text { Jenis } \\
\text { Tanah }\end{array}$ & $\begin{array}{l}\text { Nilai } \\
\text { Sensor }\end{array}$ & Keterangan & $\begin{array}{c}\text { Soil Moisture } \\
\text { Sensor }\end{array}$ & $\begin{array}{c}\text { Arduino } \\
\text { Uno }\end{array}$ \\
\hline \multirow{5}{*}{1} & \multirow{5}{*}{5 volt } & Pasir & 893 & Kering & Baik & Baik \\
\hline & & Merah & 931 & Kering & Baik & Baik \\
\hline & & Liat & 237 & Basah & Baik & Baik \\
\hline & & Gembur & 918 & Kering & Baik & Baik \\
\hline & & Humus & 957 & Kering & Baik & Baik \\
\hline \multirow{5}{*}{2} & \multirow{5}{*}{12 volt } & Pasir & 1004 & Kering & Baik & Baik \\
\hline & & Merah & 968 & Kering & Baik & Baik \\
\hline & & Liat & 296 & Basah & Baik & Baik \\
\hline & & Gembur & 988 & Kering & Baik & Baik \\
\hline & & Humus & 996 & Kering & Baik & Baik \\
\hline
\end{tabular}

Dari tabel hasil pengujian di atas dapat dilihat terdapat beberapa perbedaan nilai Soil Moisture Sensor dari lima jenis tanah yang diujikan. Perbedaan nilai sensor tersebut dikarenakan penggunaan sumber tegangan adaptor 5 volt dan 12 volt. Tegangan yang dibutuhkan oleh Arduino Uno adalah 7 sampai dengan 12 volt. Dari hasil pengujian dengan menggunakan adaptor 5 volt Arduino Uno masih dapat bekerja dengan baik, akan tetapi nilai yang terbaca oleh sensor lebih kecil dibandingkan dengan menggunakan adaptor 12 volt. Untuk mendapatkan hasil yang lebih akurat, sebaiknya gunakan sumber tegangan yang pada dasarnya dibutukan oleh Arduino Uno yaitu 7 sampai dengan 12 volt.

7. Hasil Percobaan Output

Tabel 2. Hasil Percobaan Output

\begin{tabular}{|l|l|l|l|l|l|l|}
\hline No & Voltase & $\begin{array}{c}\text { Jenis } \\
\text { Tanah }\end{array}$ & $\begin{array}{c}\text { Nilai } \\
\text { Sensor }\end{array}$ & Keterangan & Pompa & \multicolumn{1}{|c|}{ LCD } \\
\hline \multirow{2}{*}{1} & Pasir & 893 & Kering & Nyala & $\begin{array}{l}\text { Tanah: Kering(87\%) } \\
\text { Pompa: Nyala }\end{array}$ \\
\cline { 3 - 7 } & Merah & 931 & Kering & Nyala & $\begin{array}{l}\text { Tanah: Kering(91\%) } \\
\text { Pompa: Nyala }\end{array}$ \\
\cline { 3 - 7 } & Liat & 237 & Basah & Mati & $\begin{array}{l}\text { Tanah: Basah(23\%) } \\
\text { Pompa: Mati }\end{array}$ \\
\cline { 3 - 7 } & Gembur & 918 & Kering & Nyala & $\begin{array}{l}\text { Tanah: Kering(89\%) } \\
\text { Pompa: Nyala }\end{array}$ \\
\cline { 3 - 7 } & Humus & 957 & Kering & Nyala & $\begin{array}{l}\text { Tanah: Kering(93\%) } \\
\text { Pompa: Nyala }\end{array}$ \\
\hline \multirow{2}{*}{12 volt } & Pasir & 1004 & Kering & Nyala & $\begin{array}{l}\text { Tanah: Kering(98\%) } \\
\text { Pompa: Nyala }\end{array}$ \\
\cline { 3 - 7 } & Merah & 968 & Kering & Nyala & $\begin{array}{l}\text { Tanah: Kering(94\%) } \\
\text { Pompa: Nyala }\end{array}$ \\
\hline
\end{tabular}


IJSE - Indonesian Journal on Software Engineering, Vol.6, No.2, Desember 2020, 240-249

\begin{tabular}{|l|c|c|c|c|l|}
\hline & Liat & 296 & Basah & Mati & $\begin{array}{l}\text { Tanah: Basah(28\%) } \\
\text { Pompa: Mati }\end{array}$ \\
\cline { 3 - 6 } & Gembur & 988 & Kering & Nyala & $\begin{array}{l}\text { Tanah: Kering(96\%) } \\
\text { Pompa: Nyala }\end{array}$ \\
\cline { 2 - 6 } & Humus & 996 & Kering & Nyala & $\begin{array}{l}\text { Tanah: Kering(97\%) } \\
\text { Pompa: Nyala }\end{array}$ \\
\hline
\end{tabular}

Dari hasil pengujian di atas pompa celup (Submersible Pump) menyala dan LCD menampilkan data berupa tanah kering, nilai sensor, dan pompa nyala pada saat nilai sensor lebih dari 70\%. Begitu sebaliknya, pompa celup (Submersible Pump) mati dan LCD menampilkan data berupa tanah basah, nilai sensor, dan pompa mati pada saat nilai sensor kurang dari $50 \%$.

8. Hasil Percobaan Keseluruhan

Tabel 3. Hasil Percobaan Keseluruhan

\begin{tabular}{|c|c|c|c|c|c|c|c|c|}
\hline \multirow[t]{2}{*}{ No } & \multirow[t]{2}{*}{ Voltas } & \multirow{2}{*}{$\begin{array}{l}\text { Jenis } \\
\text { Tanna }\end{array}$} & \multicolumn{2}{|c|}{$\begin{array}{l}\text { Soin Mbisture } \\
\text { Sensor }\end{array}$} & \multirow{2}{*}{ Keranga } & \multirow{2}{*}{$\begin{array}{l}\text { Arduino } \\
\text { ondo } \\
\text { nno }\end{array}$} & \multirow[t]{2}{*}{ Pompa } & \multirow[t]{2}{*}{$\angle C D$} \\
\hline & & & Nilai & Kondisi & & & & \\
\hline \multirow{5}{*}{1} & \multirow{5}{*}{5 Volf } & Pasir & 893 & Baik & Kering & Baik & Nyela & $\begin{array}{l}\text { Tanah: Kering(87\%) } \\
\text { Pompa: Nolla }\end{array}$ \\
\hline & & Merah & 931 & Baik & Kering & Baik & Nyela & 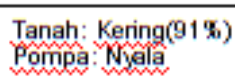 \\
\hline & & Ligt & 237 & Baik & Basah & Baik & Mati & $\begin{array}{l}\text { Tanah: Basah(23\%) } \\
\text { Poomp: Mah }\end{array}$ \\
\hline & & Gembur & 918 & Baik & Kering & Baik & Nyela & $\begin{array}{l}\text { Tanah: Kering(89x) } \\
\text { Pompa: } N \text { dala }\end{array}$ \\
\hline & & Humus & 957 & Baik & Kering & Baik & Nyela & $\begin{array}{l}\text { Tanah: Kering(93\%) } \\
\text { Poona: Niall }\end{array}$ \\
\hline \multirow{5}{*}{2} & \multirow{5}{*}{12 Volt } & Pasir & 1004 & Baik & Kering & Baik & Nyela & $\begin{array}{l}\text { Tanah: Kering }(98 \%) \\
\text { Poomp: Nyla }\end{array}$ \\
\hline & & Merah & 968 & Baik & Kering & Baik & Nala & $\begin{array}{l}\text { Tanah: Kering(94x) } \\
\text { Pompa: Nylla }\end{array}$ \\
\hline & & Ligt & 296 & Baik & Basah & Baik & Mati & $\begin{array}{l}\text { Tanah: Basah(28x) } \\
\text { Pompa: Mat }\end{array}$ \\
\hline & & Gembur & 988 & Baik & Kering & Baik & Nyela & $\begin{array}{l}\text { Tanah: Kering }(96 \%) \\
\text { Poomp: } N \text { rala }\end{array}$ \\
\hline & & Humus & 996 & Baik & Kering & Baik & Nyela & $\begin{array}{l}\text { Tanah: Kering( }(97 \text { x) } \\
\text { Pompa: Nyall }\end{array}$ \\
\hline
\end{tabular}

Saat melakukan percobaan, penulis menancapkan probe Sensor Kelembaban Tanah (Soil Moisture Sensor) ke dalam tanah. Kemudian nilai yang dibaca oleh sensor diproses oleh Arduino Uno agar dapat menjalankan perangkat output. Jika tanah dalam keadaan kering Pompa Celup (Submersible Pump) akan menyala dan LCD menampilkan data berupa tanah kering, nilai persentase sensor, dan pompa nyala. Sedangkan jika tanah dalam keadaan basah, Pompa Celup (Submersible Pump) akan mati dan LCD menampilkan data berupa tanah basah, nilai persentase sensor, dan pompa mati. Tujuan mengubah nilai sensor menjadi persen adalah untuk memudahkan petani dalam membaca nilai kelembaban tanah. Berikut ini adalah contoh mengubah nilai sensor menjadi \% (persen):

$$
\text { Pasir }=\frac{\text { NilaiSensor }}{10.23} \quad=\frac{893}{10.23}=87 \%
$$

Dari semua percobaan, hasil yang diperoleh sesuai dengan rancangan yang telah disusun sebelumnya. Hasil percobaan semua rangkaian input, proses, dan output berjalan dengan baik sesuai dengan perencanaan dan kefungsiannya alat. 


\section{E. KESIMPULAN}

Dari percobaan dan pembuatan alat penyiram sayuran otomatis ini, dapat ditarik kesimpulan sebagai berikut:

1. Sensor Kelembaban Tanah (Soil Moisture Sensor) berhasil digunakan sebagai input, sehingga dapat mendeteksi nilai kelembaban pada saat ditancapkan ke dalam tanah.

2. Sensor Kelembaban Tanah (Soil Moisture Sensor) pada alat ini terbuat dari tembaga sebagai probe.

3. Dalam tahap penerapan, Arduino Uno dapat melakukan fungsinya sebagai pengendali alat penyiram sayuran otomatis dengan baik.

4. Pompa air dapat melakukan penyiraman dengan baik pada saat sensor kelembaban tanah mendeteksi tanah dalam kondisi kering.

5. LCD dapat menampilkan data dengan baik pada saat pompa dalam keadaan mati, akan tetapi redup ketika pompa sedang menyala.

\section{REFERENSI}

Asniati, Ery Muchyar Hasiri, M. A. S. (2017). Penerapan Alat Sensor Kelembapan Tanah Dengan Mikrokontroler Atmega328 Untuk Penyiraman Tanaman Otomatis. Seminar Nasional APTIKOM (SEMNASTIKOM).

Bawotong, V. T., Mamahit, D. J., \& Sompie, S. R. U. A. (2015). Rancang Bangun Uninterruptible Power Supply Menggunakan Tampilan LCD Berbasis Mikrokontroler. E-Journal Teknik Elektro Dan Komputer.

Ekojono, Andriani Prastiwi, Cahya Rahmad, A. N. R. (2018). Pemrograman Spreadsheet Untuk Pemodelan Kontrol Rangkaian Elektronika (1st ed.). Retrieved from https://books.google.co.id/books?id=rlNyDwAAQBAJ\&pg=PA14\&dq=sensor+adalah\&hl=id $\& s a=X \& v e d=0 a h U K E w j 4 y q H 0 t 5 b j A h V 4 \_X M B H e 2 M D o c Q 6 A E I M T A C \# v=o n e p a g e \& q=s e n s$ or adalah\&f=false

Fadlilah, N. I., \& Arifudin, A. (2018). Pembuatan Alat Pendeteksi Gempa Menggunakan Accelerometer Berbasis Arduino. Jurnal Evolusi.

Marlina Sari, \& Gunawan. (2018). Rancang Bangun Alat Penyiram Tanaman Otomatis Menggunakan Sensor Kelembaban Tanah. Journal of Electrical Technology.

Maulana, E., \& Purnama, R. A. (2017). Pemanfaatan Layanan SMS Telepon Seluler Berbasis Mikrokontroler Atmega328p Sebagai Sistem Kontrol Lampu Rumah. Jurnal Teknik Komputer Amik BSI Vol. III, No. 1, Februari 2017.

Nawali, E. dedy, Sherwin, \& Tulung, N. M. (2015). Rancang Bangun Alat Penguras Dan Pengisi Tempat Minum Ternak Ayam Berbasis Mikrokontroler Atmega 16. E-Journal Teknik Elektro Dan Komputer Vol.4 No.7 (2015), ISSN : 2301-8402.

Oktavia, D. P., Hamzah, Y., Rahmondia, N. S., \& Umar, L. (2016). Karakterisasi Dan Simulasi Dioda Pn Mempergunakan Alat Uji Otomatis Berbasis Mikrokontroler Atmega8a. Jurnal Komunikasi Fisika Indonesia (KFI) Jurusan Fiska FMIPA Univ. Riau Pekanbaru. Edisi April 2016. ISSN.1412-2960.

Prayama, D., Yolanda, A., \& Pratama, A. W. (2018). Rancang Bangun Alat Pengontrol Penyiram Tanaman Otomatis Menggunakan Sensor Kelembaban Tanah Di Area Pertanian. Jurnal RESTI (Rekayasa Sistem Dan Teknologi Informasi). https://doi.org/10.29207/resti.v2i3.621

R.Arifin, R. B. \&. (2016). SKM (Sukses Kuasai Materi) IPA SMP Kelas VII, VIII, IX. Retrieved from https://books.google.co.id/books?id=zMJGDwAAQBAJ\&pg=PA372\&dq=transformator+ada lah\&hl=id\&sa=X\&ved=0ahUKEwixwpaF35XjAhWHK48KHUZvCyoQ6AEILjAB\#v=onepage $\& \mathrm{q}=$ transformator adalah\&f=false

Sahyar. (2016). Algoritma Pemrograman Menggunakan Matlab (1st ed.). Retrieved from 
IJSE - Indonesian Journal on Software Engineering, Vol.6, No.2, Desember 2020, 240-249

https://books.google.co.id/books?id=0wovDwAAQBAJ\&pg=PA2\&dq=bahasa+pemrograma $\mathrm{n}+$ adalah\&hl=id\&sa=X\&ved=0ahUKEwiKqozg25rjAhUKql8KHcAkDA8Q6AEIODAD\#v=one page $\& q=$ bahasa pemrograman adalah $\& f=f a l s e$

Sokop, Jendri Steven, Dringhuzen J. Mamahit, S. R. U. A. S. (2016). Trainer Periferal Antarmuka Berbasis Mikrokontroler Arduino Uno. E-Journal Teknik Elektro Dan Komputer.

Widiharto. (2017). Sistem penyiram tanaman yang dapat dimonitor dengan komputer dan perangkat mobile. SISTEM PENYIRAM TANAMAN YANG DAPAT DIMONITOR DENGAN KOMPUTER DAN PERANGKAT MOBILE. 